\title{
Characteristics and treatment of temporal lobe epilepsy with a history of complicated febrile convulsion
}

\author{
Kousuke Kanemoto, Natori Takuji, Jun Kawasaki, Itsuo Kawai
}

\begin{abstract}
This study aimed to examine the close correlation between complicated febrile convulsions (CFC) and medial temporal lobe epilepsy and to delineate characteristics of temporal lobe epilepsy with CFC. Patients with temporal lobe epilepsy were divided into those with a prior episode of CFC ( $n=52)$, those with febrile convulsions other than CFC, and those witout either $(n=345)$. Clinical constellations, neuroimaging, drug resistance, and effects of temporal lobectomy of the three groups were compared. A close association between CFC and temporal lobe epilepsy was confirmed. The salient features of temporal lobe epilepsy with CFC were early age at onset of habitual seizures (about 10 years), the predominance of autonomic auras, and a high incidence of MRI evidence of unilateral medial temporal sclerosis. Patients with temporal lobe epilepsy with prior CFC had an excellent outcome after surgery, by contrast with an unfavourable response to drug therapy. The surgical results were discouraging in patients with temporal lobe epilepsy without history of any febrile convulsions and without solid brain tumours. These results indicate surgical intervention as the choice of therapy in a substantial number of patients with temporal lobe epilepsy with a history of CFC.

(F Neurol Neurosurg Psychiatry 1998;64:245-248)
\end{abstract}

Keywords: temporal lobe epilepsy; febrile convulsion; mesial temporal sclerosis

There has been much controversy as to whether a causal relation exists between febrile convulsions in infancy and temporal lobe epilepsy. Whereas early authors in England strongly suggested that complicated febrile convulsions (CFC) was an important source of mesial temporal sclerosis and the subsequent development of temporal lobe epilepsy, ${ }^{1-4}$ this specific relation has been denied categorically by several subsequent investigators. ${ }^{56}$ However, recently, the relevance of febrile convulsion during early childhood began to attract attention again. ${ }^{7}$ Some excellent surgical results, ${ }^{8-12}$ combined with an unfavourable outcome of drug therapy ${ }^{13}$ of temporal lobe epilepsy with mesial temporal sclerosis augmented the importance of this renewed awareness. This study attempts to reaffirm that temporal lobe epilepsy with a history of CFC constitutes a definite subgroup in temporal lobe epilepsy and that prior CFC serves as an indicator of surgical intervention to relieve temporal lobe epilepsy.

Subjects and methods

The case records of all outpatients seen by the seizure clinic at the Kansai Regional Epilepsy Center from 1987 to 1993 were reviewed. In 2563 patients, different types of epilepsies were diagnosed. Of these 2563 patients, 103 had had prior episodes of CFC. We ranked episodes of febrile convulsions lasting for more than 15 minutes or with a transient postictal neurological deficit as CFC. We classified these patients into five categories and determined which type of epilepsy was closely tied to a history of CFC. This classification was based on an international classification plus dichotomy of symptomatic localisation related epilepsy into temporal and non-temporal groups. We defined temporal lobe epilepsy as epilepsy having both interictal temporal EEG foci and complex partial seizures.

We further subdivided the patients with temporal lobe epilepsy into three groups: those with CFC (CFC group; $n=52$ ), those with simple febrile convulsions (SFC; SFC group; $n=52$ ), and those without either SFC or CFC (non-FC group; n=345). Febrile convulsions except CFC were counted as SFC. We compared clinical features, response to drug therapy, and findings of EEG and MRI of the two groups. According to Engel's classification, ${ }^{14}$ the effect of temporal lobectomy was analysed as a function of CFC.

For statistical analysis, we applied general linear models (Duncan's multivariant comparison). Further, we added categorical data modelling in a form of analysis of variance to the seizure constellation. The figures in parentheses indicate confidence intervals. 


\section{Results}

HISTORIES OF SFC AS A FUNCTION OF EPILEPSY TYPES

Forty one of the 2568 patients were classified into idiopathic localisation related epilepsy. Three of the 41 patients had had CFC (7\%). A total of 280 patients had idiopathic generalised epilepsy. Of these, only two patients had had a history of CFC (1\%). Among 674 patients with non-temporal symptomatic localisation related epilepsy, 21 had had CFC (3\%). The CFC preceded habitual seizures in eight of 352 patients with symptomatic or cryptogenic generalised epilepsy $(2 \%)$. As many as 52 of the 449 patients with temporal symptomatic localisation related epilepsy had had CFC (12\%). Histories of CFC were significantly more often encountered in this group of patients $\left(\chi^{2}\right.$ $=80.7, \mathrm{p}<0.001$ ).

CHARACTERISTICS OF PATIENTS WITH TEMPORAL LOBE EPILEPSY WITH A HISTORY OF SFC (TABLE 1 ) There were 345 patients (149 females and 196 males) in the non-FC group, 52 (22 females and 30 males) in the SFC group, and 52 (27 females and 25 males) in the CFC group. The mean age at seizure onset (non-febrile) was $14.7(7.1-22.3)$ years in the non-FC group, 13.7 (6.4-21.0) years in the SFC group, and 10.5 (7.5-13.5) years in the FC group. Duncan's multivariant comparison disclosed that the age at onset of the CFC group was significantly earlier than that of the non-FC group $(F(2.423)=3.11, \mathrm{p}=0.0455)$. The mean duration of epilepsy at the time of examination was 14.9 (8.6-21.2) years in the non-FC group, 14.1 (5.3-22.9) years in the SFC group, and 14.4 (12.1-16.7) years in the CFC group. More patients in the CFC group and in the SFC group than in the non-FC-group $(17 \% \mathrm{v}$ $11 \%$ ) had episodes of psychosis.

Table 1 Clinical and laboratory data

\begin{tabular}{llll}
\hline & $\begin{array}{l}\text { Non-FC group } \\
(n=345)\end{array}$ & $\begin{array}{l}\text { SFC group } \\
(n=52)\end{array}$ & $\begin{array}{l}\text { CFC group } \\
(n=52)\end{array}$ \\
\hline Sex (F/M) & $149 / 196$ & $22 / 30$ & $27 / 25$ \\
Onset (mean (95\% CI)) & $14.7(22.3)$ & $13.7(21.0)$ & $10.5(13.5)$ \\
$\begin{array}{l}\text { Duration of illness (mean (95\% CI)) } \\
\text { Psychosis (n (\%)) }\end{array}$ & $14.9(21.2)$ & $14.1(22.9)$ & $14.4(16.7)$ \\
Seizures (n (\%)): & $36 / 345(10)$ & $9 / 52(17)$ & $9 / 52(17)$ \\
$\quad$ CPS & $345 / 345(100)$ & $52 / 52(100)$ & $52 / 52(100)$ \\
SGTC & $225 / 345(65)$ & $35 / 52(67)$ & $30 / 52(58)$ \\
$\quad$ Sleep & $34 / 345(10)$ & $6 / 52(12)$ & $4 / 52(8)$ \\
SPS: & & & \\
$\quad$ Autonomic & $61 / 345(18)$ & $6 / 52(24)$ & $16 / 52(31)$ \\
$\quad$ Experiential & $44 / 345(13)$ & $2 / 52(4)$ & $4 / 52(8)$ \\
$\quad$ Anxiety & $26 / 345(8)$ & $5 / 52(10)$ & $4 / 52(8)$ \\
$\quad$ Motor & $18 / 345(5)$ & $2 / 52(4)$ & $3 / 52(6)$ \\
$\quad$ Aphasic & $18 / 345(5)$ & $1 / 52(2)$ & $4 / 52(8)$ \\
$\quad$ Elemen visual & $12 / 345(3)$ & $2 / 52(4)$ & $0 / 52(0)$ \\
UHS on MRI (n (\%)) & $23 / 65(35)$ & $6 / 14(43)$ & $15 / 21(71)$ \\
\hline
\end{tabular}

UHS $=$ unilateral hippocal sclerosis.

Table 2 Effects of temporal lobectomy

\begin{tabular}{|c|c|c|c|}
\hline & $\begin{array}{l}\text { Non-FC group } \\
n(\%)\end{array}$ & $\begin{array}{l}S F C \text { group } \\
n(\%)\end{array}$ & $\begin{array}{l}C F C \text { group } \\
n(\%)\end{array}$ \\
\hline \multicolumn{4}{|l|}{ Operated: } \\
\hline & $4 / 8(50)$ & $14 / 17$ & $12 / 13(92)$ \\
\hline II & $1 / 8(13)$ & $3 / 17(18)$ & $1 / 13(8)$ \\
\hline III/IV & $3 / 8(38)$ & & \\
\hline \multicolumn{4}{|l|}{ Not operated: } \\
\hline $\mathrm{I}^{\prime}$ & $48 / 187(26)$ & $7 / 35(20)$ & $6 / 37(16)$ \\
\hline
\end{tabular}

$\mathrm{I}=$ complete remission or only auras $(2 \mathrm{y}) ; \mathrm{II}=$ complete remission or only auras $(1 \mathrm{y}) ; \mathrm{II}=$ more than $90 \%$ reduction of seizures; III/IV = no improvement or exacerbation of seizures.
We confirmed MRI evidence of unilateral hippocampal atrophy in 23 of 65 patients in the non-FC group (35\%), six of 14 patients in the SFC group (43\%), and 15 of 21 patients in the CFC group $(71 \%)$. Unilateral hippocampal atrophy was significantly more often encountered in the CFC group than the non-FC group and the SFC group $(F(2.97)=4.88$, $\mathrm{p}=0.095)$.

Except for autonomic auras, no seizure types were significantly more often encountered as a function of febrile convulsions. Autonomic auras occurred significanly more often in the CFC group than the non-FC and the SFC groups $(F(2.446)=3.54, \mathrm{p}=0.298)$. Categorical modelling analysis as a function of seizure types agreed with this result. Only autonomic auras showed significance $\left(\chi^{2}=6.40, p=0.41\right)$.

SURGICAL OUTCOME OF PATIENTS WITH TEMPORAL LOBE EPILEPSY WITH AND WITHOUT CFC (TABLE 2)

Anterior temporal lobectomy was performed in 13 patients in the CFC group, in 17 in the SFC group, and in eight in the non-FC group. Among them, an eventual seizure free state of two years or more, whether the patient was seizure free since surgery or not, was achieved in $92 \%$ of the patients in the CFC group, in $82 \%$ of those in the SFC group, and only $50 \%$ of those in the non-FC group (Engel's class 1). ${ }^{14}$ Three patients in the non-FC group $(n=3)$ exhibited a poor postoperative result estimated as class 3 or class 4 outcome in Engel's classification. No patient in the CFC and SFC groups exhibited an unfavourable outcome of class 3 or less.

It was noteworthy that three out of four patients with a class 1 surgical result had solid brain tumours in the non-FC group. No solid tumours was found in either the CFC or SFC group.

By contrast with the excellent surgical outcome, $84 \%$ of the medically treated patients in the CFC group could not achieve even a one year seizure free state. Those in the SFC group exhibited a better (20\%), and those in the non-FC group a much better $(26 \%)$ one year remission rate with drug therapy.

\section{Discussion}

Whether or not temporal lobe epilepsy may be a consequence of prolonged febrile convulsions has been long disputed. ${ }^{1-61516}$ Annegers et al, ${ }^{17}$ admitting that a history of complicating febrile convulsions increased the risk of subsequent epilepsy, postulated that epileptic seizures were of various clinical types, in a distribution similar to that found in an extensive review of epilepsy in a general population. Leviton and Cowan $^{18}$ also questioned a specific causal relation between prolonged febrile convulsions and temporal lobe epilepsy. Lee $e t a l^{\overline{ }}$ and Sofijanov et $a l^{6}$ were more direct. These authors overtly denied the role of febrile seizures in the genesis of temporal lobe epilepsy that had been based on pathohistological findings. A careful scrutiny of these data, however, seemingly contradicted the view based on the Maudsley series, indicating that this discrepancy was more 
apparent than real. None of these opponents of Falconer's hypothesis analysed the correlation of temporal lobe epilepsy with prolonged (or complex) febrile convulsions but with febrile convulsions in general. By contrast, the results of the study that had investigated temporal lobe epilepsy with special attention to prolonged febrile convulsions or febrile convulsions with focal nature supported this correlation. ${ }^{19}{ }^{20}$ The present study also confirmed that prolonged febrile convulsions or febrile convulsions accompanied by postictal neurological deficits were significantly more often encountered in temporal lobe epilepsy.

There remains the possibility that a common factor in some patients predisposes them to both febrile seizures in infancy and temporal lobe epilepsy later in life or that febrile seizures are the earliest manifestation of temporal lobe epilepsy in patients with pre-existing low seizure thresholds. However, we preferred to assign a more active causative role to prolonged febrile convulsion. Recently, Maher and McLachlan ${ }^{21}$ found that not the total number, the maximum number in any day, or the age at onset but the duration of the febrile convulsions was the most important determinant of the association between temporal lobe epilepsy and febrile convulsions. If an unknown common factor predisposed patients to both febrile convulsions in infancy and temporal lobe epilepsy later in life and there is no direct causal relation between febrile convulsions and temporal lobe epilepsy, this common factor should have not only prolonged but also increased the frequency of febrile convulsions in the series of Maher and McLachlan. In relation to this, female preponderance in the CFC group was also noted. Taylor and Ounsted ${ }^{22}$ postulated that the female brain is more susceptible to the trauma during the early months of life. Female preponderance in the CFC group supported this and suggested that febrile convulsions, occurring in early infancy as a rule, lead to more severe consequences in females. Regardless of the causal relation, one thing is clear. As there is no similar correlation in other types of epilepsy a close association between a history of complicated febrile convulsions and temporal lobe epilepsy cannot be ignored.

The triad of early prolonged febrile convulsion, predominant age of onset of habitual seizures earlier than 10 years, and medial temporal sclerosis had been found in the Maudsley series. After a long period of neglect, French et $a l^{23}$ revived and refined the view of Falconer and his colleagues by establishing the concept of medial temporal lobe epilepsy firmly on the basis of in depth EEG findings and as a result of exclusion of all the circumscribed lesions. They also stressed the predominance of autonomic auras. Gastaut et $a l,{ }^{24}$ in their classic work, also noted that autonomic auras were notably more frequent in patients with temporal lobe epilepsy as a sequel to the hemiconvulsions, hemiplegia, and epilepsy syndrome. It was noteworthy that this predominance of autonomic auras in medial temporal lobe epilepsy was coupled with good surgical outcome by Duncan and Sagar. ${ }^{8}$ The charac- teristics of the CFC group of patients with temporal lobe epilepsy that we confirmed statistically in this study agreed very well with the salient features of medial temporal lobe epilepsy pointed out by French et al-namely, relatively early age (about 10 years) at habitual seizure onset; the predominance of abdominal visceral auras; and a high incidence of MRI evidence of unilateral medial temporal abnormalities. In conclusion, our study showed that temporal lobe epilepsy with CFC constitutes a definite subtype of temporal lobe epilepsy and that this exhibits roughly the same clinical constellation as medial temporal lobe epilepsy, as defined by French et al.

Interestingly, the series of temporal lobe epilepsy presented by Schmidt et al $l^{13}$ provides evidence that febrile seizures are associated with a subgroup of patients with medically refractory complex partial seizures. In their series, seizure control was significantly poorer in patients with previous febrile convulsions. This unfavourable outcome to drug therapy was also noted in the CFC group of our study, although the difference fell short of significance. By contrast, the surgical outcome of this subtype of temporal lobe epilepsy has been shown to be excellent recently. ${ }^{8-12}$ In our study, almost all the patients with CFC have been free from complex partial seizures since surgery. This was in sharp contrast with the rather discouraging surgical results in patients with temporal lobe epilepsy without a history of febrile convulsion. Considering the well demarcated clinical features and the medical intractability, this favourable outcome after temporal lobectomy encourages surgical intervention in this particular group of temporal lobe epilepsy with a history of CFC.

1 Falconer MA, Taylor DC. Surgical treatment of drugresistant epilepsy due to mesial temporal sclerosis. Etiology and significance. Arch Neurol 1968;19:353-61.

2 Ounsted C, Lindsay J. Norman R. Biological factors in temporal lobe epilepsy. Clinic in developmental medicine. Heinemann, London, 1966:22.

3 Davidson S, Falconer MA. Outcome of surgery in 400 children with temporal lobe epilepsy. Lancet 1975; i:1260-3.

4 Lindsay J, Ounsted C, Richards P. Long-term outcome in children with temporal lobe seizures. IV: Genetic factors,
chents children with temporal lobe seizures. IV: Genetic factors,
febrile convulsions and the remission of seizures. Dev Med Child Neurol 1980;22:429-39.

5 Lee K, Diaz M, Melchior JC. Temporal lobe epilepsy-not a consequence of childhood febrile convulsions in Denmark. Acta Neurol Scand 1981;63:231-6.

6 Sofijanov N, Sadikario A, Dukovski M, et al. Febrile convulsions and later development of epilepsy. Am $\mathcal{F}$ Dis Child 1983;137:123-6.

7 French JA, Williamson PD, Thadani VM, et al. Characteristics of medial temporal lobe epilepsy: I. Results of history and physical examination. Ann Neurol 1993;34:774-80.

8 Duncan JS, Sagar HJ. Seizure characteristics, pathology, and outcome after temporal lobectomy. Neurology 1987;37: Out-9.

9 Jack CR, Sharbrough FW, Cascino GD, et al. Magnetic resonance image-based hippocampal volumetry: correlaresonance image-based hippocampal volumetry: correla-
tion with outcome after temporal lobectomy. Ann Neurol tion with outcom

10 Kuzniecky R, Burgard S, Faught E, et al. Predictive value of magnetic resonance imaging in temporal lobectomy. Ann Neurol 1993;50:65-9.

11 Garcia PA, Laxer KD, Barbaro NM, et al. Prognostic value of qualitative magnetic resonance imaging hippocampal abnormalities in patients undergoing temporal lobectomy for medically refractory seizures. Epilepsia 1994;35:520524 .

12 Berkovic SF, McIntosh AM, Kalnins RM, et al. Preoperative MRI predicts outcome of temporal lobectomy: an actuarial analysis. Neurology 1995;45:1358-63.

13 Schmidt D, Tsai JJ, Janz D. Febrile seizures in patients with complex partial seizures. Acta Neurol Scand 1985;72:68-71.

14 Engel J Jr, Van Ness PC, Rasmussen TB, et al. Outcome with respect to epilepstic seizures. In: Engel J Jr, ed. Surgical treatment of the epilepsies, 2nd ed. New York: Raven, 1993:609-21. 
15 Rocca WA, Sharbrough FW, Hauser WA, et al. Risk factors for complex partial seizures: a population-based case$7 ; 21: 22-31$

16 Nelson KB, Ellenberg JH. Prognosis in children with febrile seizures. Pediatrics 1978;61:720-7.

17 Annegers JF, Hauser WA, Elveback LR, et al. The risk of epilepsy following febrile convulsions. Neurology 1979;29:
297-303.

18 Leviton A, Cowan LD. Do febrile seizures increase the risk of complex partial seizures? An epidemiologic assessment. In: Nelson KB, Ellenberg JH, eds. Febrile seizures. New York: Raven, 1981:65-74

19 Wallace SA. Spontaneous fits after convulsions with fever. Arch Dis Child 1977;52:192-6.

20 Aicardi J, Chevrie JJ. Febrile convulsions: neurological sequelae and mental retardation. In: Brazier MAB, Coceani
F, eds. Brain dysfunction in infantile febrile convulsions. New York: Raven, 1976:247-57.

21 Maher J, McLachlan RS. Febrile convulsions. Is seizure duration the most important predictor of temporal lobe

22 Taylor DC, Ounsted C. Biological mechanisms influencing the outcome of seizures in response to fever. Epilepsia 1971;12:33-45.

23 Williamson PD, French JA, Thadani VM, et al. Characteristics of medial temporal lobe epilepsy: II. Interictal and ictal scalp electroencephalography, neuropsychological testing, 1993;34:781-7

24 Gastaut H, Poirier F, Payan H, et al. HHE syndrome: hemiconvulsions, hemiplegia, epilepsy. Epilepsia 1959/60;1: 418-47. 